\title{
Ursula Baumgardt et Jean Derive (dirs), Littérature africaine et oralité
}

\section{Saida Hamouyehy}

\section{Q OpenEdition}

10 Journals

\section{Édition électronique}

URL : http://journals.openedition.org/studifrancesi/1647

DOI : 10.4000/studifrancesi. 1647

ISSN : 2421-5856

Éditeur

Rosenberg \& Sellier

\section{Édition imprimée}

Date de publication : 1 novembre 2014

Pagination : 643-644

ISSN : 0039-2944

\section{Référence électronique}

Saida Hamouyehy, «Ursula Baumgardt et Jean Derive (dirs), Littérature africaine et oralité », Studi Francesi [En ligne], 174 (LVIII | III) | 2014, mis en ligne le 01 novembre 2014, consulté le 18 septembre 2020. URL : http://journals.openedition.org/studifrancesi/1647 ; DOI : https://doi.org/10.4000/ studifrancesi. 1647

Ce document a été généré automatiquement le 18 septembre 2020.

\section{(c)}

Studi Francesi è distribuita con Licenza Creative Commons Attribuzione - Non commerciale - Non opere derivate 4.0 Internazionale. 


\title{
Ursula Baumgardt et Jean Derive (dirs), Littérature africaine et oralité
}

\author{
Saida Hamouyehy
}

\section{RÉFÉRENCE}

URSULA BAUMGARDT et JEAN DERIVE (dirs), Littérature africaine et oralité, Paris, Karthala, 2013, pp. 172.

1 Cet ouvrage publié sous la direction d'Ursula BAUMGARDT et Jean DERIVE recueille les actes des journées d'études de l'APELA, qui ont eu lieu le 23 et le 24 septembre 2010 chez LLACAN (Langage, langues et cultures d'Afrique noire). Comme le titre l'indique, les spécialistes cherchent à mieux comprendre le rôle de l'oralité dans les littératures africaines. Une des richesses de ce livre est qu'il prend en considération l'aspect multiculturel et polyglotte du continent africain en analysant en effet autant les productions africaines francophones que celles de langues régionales ou kabyles. Chaque fois en abordant la même question: dans quelle mesure les œuvres écrites s'approchent de l'oralité?

Littérature africaine et oralité est organisé en deux parties, la première se concentre d'abord sur la littérature écrite avant de donner la place à une autre originalité du livre, à des recherches sur la littérature orale contemporaine. Pour la littérature francophone Marie-Rose ABOMO MAURIN présente l'A-fric de Jacques Fame Ndogo, une fable politique où les personnages sont des animaux intelligents. Clément EFFOH EHORA passe en revue quelques romanciers ouest-africains qui utilisent des formules introductives ou clausulaires typiques de l'oralité. Quant à la littérature en langue régionale, Saoudé ALI et Jean DERIVE analysent l'œuvre de Yakubu Ramat Balaraba Alhaki Kuykuy Ne..., basée sur des proverbes hausa. Mélanie BOURLET nous présente le roman peul Ndikkiri joom moolo de Yero Dooro Diallo où le personnage principal non-casté, contrairement aux conventions, veut devenir musicien. Quant à l'article de Nguettia 
KOUADIO, il s'efforce de montrer comment l'oralité imprègne la poésie écrite à partir de D.E.J.A.V.U. de Noël X. Ebony.

3 Dans la deuxième partie qui se consacre à l'actualité de la littérature orale, Amar AMEZIANE, Serenah tomBA et Kelly Marlène miLÉBOU nDJAVÉ étudient la littérature kabyle, où l'oralité est de plus en plus médiatisée. Kelly Marlène MILÉBOU NDJAVÉ nous présente Pierre-Claver Akendengué et son art de chanter le conte.

4 L'ouvrage de Baumgardt et de Derive n'arrive pas à une conclusion bien définie sur la question initiale, à savoir dans quelle mesure les œuvres écrites s'approchent de l'oralité. Il illustre en revanche par plusieurs exemples l'originalité et la diversité de la littérature écrite africaine contemporaine, contaminée par l'oralité, ancien moyen de communication typiquement africain. Nous regrettons que les articles de ce livre se penchent sur des histoires africaines sans les contextualiser; dommage, le lecteur que nous sommes n'a pas été en mesure de bien suivre la démonstration savante, une mise en contexte aurait pu facilement nous diriger vers une meilleure compréhension. 